has contributed very greatly to the development of technical education not only in Salford but also in the north-western region and nationally. The Salford College has always been an important institution in the region, but during Dr. Venables's term of office it has grown in its service and influence. All its departments have increased their facilities to students, both full- and part-time, and in particular the 'sandwich system' has been established; it now has some 430 students, and this number is expected to grow to 1,100 in five years time. This system, in which students alternate periods in the College with periods in industry, shows that Dr. Venables has the full confidence of industrialists in the area, and it may be expected that this work will be an important contribution to the improvement of technological services in the region. But Dr. Venables's work has not been limited to his own area. In 1951 he visited the United States under the Fulbright Scheme to study the work of universities and technical colleges linked with industry, and to see schemes for industrially sponsored research. Since 1954 he has been chairman of the Regional Academic Board, which includes university, technical college and industrial mombers, and he is also a member of the National Advisory Council for Education in Industry and Commerce. He has also held high office in the Association of Technical Institutions and in the Association of Principals of Technical Institutions. He has recently published an authoritative book, "Technical Education" (see Nature, Feb. 18, p. 296), and holds a Leverhulme Research Fellowship to study "Education and Training Schemes in certain industries with special reference to the work of technical colleges and the needs of smaller firms". $\mathrm{He}$ was vice-chairman of the national committee which produced the report on "Liberal Studies in a Technical Age". $\mathrm{H}_{\Theta}$ is leaving Salford after having devised and started an extension scheme expected to cost $£ 1,500,000$. He will be greatly missed in the region on account of his knowledge, energy and good fellowship.

\section{Edward Goodrich Acheson (1856-1931)}

EDWARD Goodrich Acheson was born on March 9, 1856, at Washington, Pa. Of Scottish and English ancestry, he died in 1931, and during his life was granted patents for seventy inventions. Outstanding were an industrial method of producing silicon carbide electrothermally (1891), the manufacture of graphite from a coke base in the electric furnace (1893) and the manufacture of pure graphite of high crystallinity (1896 and 1900). Having prepared pure graphite in the electric furnace, Acheson turned his attention to means of disintegrating it and preparing colloidal dispersions. He succeeded in this (1906-7) and made available stabilized dispersions of graphite for lubrication. Colloidal graphite is used to-day to aid the lubrication of mechanical equipment of all kinds, in filament wire drawing and for the production of electrically conducting coatings. At the 150th anniversary of the signing of the Declaration of Independence in 1926, the United States Post Office exhibited seventeen patents of F. G. Acheson which had benefited industry. The Smithsonian Institution has a permanent Edward Goodrich Acheson Exhibit, showing products springing from his inventions and the medals awarded to him. He was awarded the Rumford Medal of the American Academy of Arts and Sciences (1908), the Perkin Medal of the American Section of the Society of
Chemical Industry (1910), and the University of Pittsburgh conferred on him the honorary degree of doctor of science in 1909. The present annual world production of silicon carbide for machining and grinding runs into many thousands of tons, with plants in more than twenty countries. Electric furnace graphite in electrode and powder form, made by Acheson's process, is produced in very large quantities, in Britain, the United States, France and other countries. It was this pure form of graphite that was used as moderator in the first nuclear reactor in the world to be built, at Chicago. At one time Acheson was an assistant to Thomas Edison at Menlo Park and carried out development work on early incandescent lamps, while he installed the first electric lighting system in Europe, at Milan. He lived for some time in London.

\section{Recent Solar Activity}

Two streams of large sunspots, in latitudes $20^{\circ} \mathrm{N}$. and $20^{\circ} \mathrm{S}$., were visible on the Sun's disk during February. The total area of sunspots on February 20 was greater than that of any day since 1947, the previous sunspot maximum year. The most recent sunspot minimum occurred during the first half of 1954. Since that time sunspot activity has, with the usual variations, increased steadily, and about twenty-five sunspot groups have exceeded in area 500 millionths of the Sun's hemisphere within the past fourteen months. The mean daily sunspot number for the months November 1955-February 1956 has been around 90 . The steepness of the rise in the sunspot cycle is believed to indicate the 'height' of the coming maximum, so that if sunspot activity continues to increase, mean daily sunspot numbers in excess of 150 may be expected by the end of 1956. The actual epoch of sunspot maximum would probably occur during the first half of 1957 .

On February 23 at 0330 hours U.T., a large flare was observed on the Sun from an Indian observatory; it lasted until $0510 \mathrm{~h}$. Complete Dellinger-type 'fadeouts' of radio circuits from Hong Kong and Singapore occurred between $0345 \mathrm{~h}$. and $0500 \mathrm{~h}$., such as are normally associated with the ultra-violet light from a large flare. A large increase of cosmic-ray flux was simultaneously recorded by many types of recorders in different parts of the world. A sea-level meson recorder in Great Britain showed a 100 per cent increase in counting-rate starting during the tenminute period $0340-0350 \mathrm{~h}$. Previous increases associated with solar flares on similar instruments have only rarely occurred and have never exceeded 40 per cent. The flux gradually diminished and normal counting-rate was resumed two to three hours later. Lower-energy cosmic radiation probably continued to arrive from the Sun.

\section{Research in Industry and Government}

Is the third E. F. Armstrong Memorial Lecture to the Royal Society of Arts, given on November 23, Dr. B. K. Blount, deputy secretary of the Department of Scientific and Industrial Research, reviewed the growth of research in industry in Great Britain, describing the general form of the organization it had taken, and discussed some of the implications. Fundamental research, he thought, is best done in the universities; but applied, or industrial, research is best done directly by industry in its own laboratories, and the more this work is located physically within the industry the better service it will give. In particular, only thus will the research really corre- 